\title{
Clinical remission and subsequent relapse in patients with juvenile idiopathic arthritis: predictive factors according to therapeutic approach
}

Mireia Castillo-Vilella $a^{1,2,3,4^{*}}$ D, Nuria Giménez ${ }^{4,5,6}$ (D) , Jose Luis Tandaipan ${ }^{2,7,8}$, Salvador Quintana ${ }^{9}$ and Consuelo Modesto ${ }^{3,10}$

\begin{abstract}
Background: Juvenile idiopathic arthritis constitutes a significant cause of disability and quality of life impairment in pediatric and adult patients. The aim of this study was to ascertain clinical remission (CR) and subsequent relapse in juvenile idiopathic arthritis (JIA) patients, according to therapeutic approach and JIA subtype. Evidence in literature regarding its predictors is scarce.

Methods: We conducted an observational, ambispective study. Patients diagnosed of JIA, treated with synthetic and/or biologic disease modifying antirheumatic drugs (DMARD) were included and followed-up to December 31st, 2015. Primary outcome was clinical remission defined by Wallace criteria, both on and off medication. In order to ascertain CR according to therapeutic approach, DMARD treatments were divided in four groups: 1) synthetic DMARD (sDMARD) alone, 2) sDMARD combined with another sDMARD, 3) sDMARD combined with biologic DMAR $\mathrm{D}$ (bDMARD), and 4) bDMARD alone.
\end{abstract}

Results: A total of 206 patients who received DMARD treatment were included. At the time the follow-up was completed, $70 \%$ of the patients in the cohort had attained CR at least once (144 out of 206), and 29\% were in clinical remission off medication (59 out of 206).

According to treatment group, CR was more frequently observed in patients treated with synthetic DMARD alone (53\%). Within this group, CR was associated with female sex, oligoarticular persistent subtypes, ANA positivity, Methotrexate treatment and absence of HLA B27, comorbidities and DMARD toxicity. 124 DMARD treatments (62\%) were withdrawn, $64 \%$ of which relapsed. Lower relapse rates were observed in those patients with persistent oligoarticular JIA (93\%) when DMARD dose was tapered before withdrawal (77\%).

\footnotetext{
* Correspondence: mireiacastillo.vi@gmail.com

Salvador Quintana is retired.

'Department of Rheumatology, Hospital UniversitariSagrat Cor, C/ Londres, 28-38 3rd floor, 08029 Barcelona, Spain

${ }^{2}$ Department of Rheumatology, Hospital UniversitariMútua Terrassa, Terrassa, Spain

Full list of author information is available at the end of the article
}

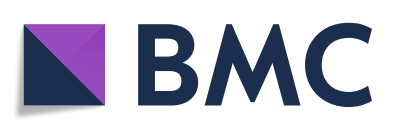

(- The Author(s). 2021 Open Access This article is licensed under a Creative Commons Attribution 4.0 International License, which permits use, sharing, adaptation, distribution and reproduction in any medium or format, as long as you give appropriate credit to the original author(s) and the source, provide a link to the Creative Commons licence, and indicate if changes were made. The images or other third party material in this article are included in the article's Creative Commons licence, unless indicated otherwise in a credit line to the material. If material is not included in the article's Creative Commons licence and your intended use is not permitted by statutory regulation or exceeds the permitted use, you will need to obtain permission directly from the copyright holder. To view a copy of this licence, visit http://creativecommons.org/licenses/by/4.0/. The Creative Commons Public Domain Dedication waiver (http://creativecommons.org/publicdomain/zero/1.0/) applies to the data made available in this article, unless otherwise stated in a credit line to the data. 
Conclusions: More than two thirds of JIA patients attained CR along the 9 years of follow-up, and nearly one third achieved CR off medication. Females with early JIA onset, lower active joint count and ANA positivity were the ones achieving and sustaining remission more frequently, especially when receiving synthetic DMARD alone and in the absence of HLA B27, comorbidities or previous DMARD toxicity.

Keywords: Juvenile arthritis, Remission, DMARD, Withdrawal, Relapse, Predictor

\section{Background}

Juvenile idiopathic arthritis is the most common chronic rheumatic disease in childhood. This term comprises an heterogenous group of arthritis of unknown aetiology, each of which has differential genetics, etiopathogenesis, onset age and disease outcomes [1,2]. It constitutes a significant cause of disability and quality of life impairment in JIA pediatric and adult patients [3-5].

Recent advances in JIA treatment addressing more specific targets have led to better short and long-term disease outcomes. Evidence throughout the last decade has shown that an early and tight treatment to target approach of the disease increases the likelihood of achieving and sustaining clinical remission over time [6-9]. Nevertheless, a notable proportion of patients relapse, either while still on medication or after its withdrawal [10-12].

On the other hand, it seems reasonable to withdraw all medications in those patients that already have achieved CR to avoid the costs and possible adverse events derived of maintaining it over time. In this scenario, the main concern to most physicians is the occurrence of a relapse, which has shown to be frequent in most studies [13-15]. In those patients who attain $C R$ despite having a more aggressive course of the disease, maintaining tapered DMARD doses could increase the likelihood of sustaining a quiescent status of the disease over time, and avoid relapse after treatment withdrawal $[9,13,15,16]$.

No consistent evidence or guidelines are available regarding how or when to withdraw DMARD, or whether to do it abruptly or after the dose has been gradually tapered. Some studies have analysed the possible predictors of flare in patients in CR on and off medication, obtaining heterogeneous and conflicting results. Moreover, those predictors have not been validated to address therapeutic strategies in a real practice setting. This fact is partly explained by the heterogeneity within JIA categories, which consequently generates great variability in the definition and composition of study populations. In addition, evidence in literature has shown heterogeneity in clinical remission and inactive disease definitions, as well as significant variability in therapeutic strategies carried out by pediatric rheumatologists in JIA treatment $[13,15,17,18]$.

Few studies have analysed the prevalence and likelihood of CR regarding the therapeutic approach, which stands the aim of our study. Administering synthetic and biologic DMARD alone or combined is of significant relevance due to its influence on its tolerability, adherence, safety, efficacy and on subsequent disease outcomes $[9,19,20]$.

\section{Methods}

We conducted a single-center, observational, retrospective-prospective study of JIA patients who were attended at Vall d'Hebrón University Hospital's Pediatric Rheumatology Unit. This tertiary care hospital is a reference centre for JIA patients in Catalonia (Spain), where the mean JIA incidence was estimated to be of 6.9 per 100,000 children by 2010 [21].

A retrospective cohort was created on January 1st, 2012, in which patients diagnosed of JIA, treated with DMARD, and followed-up to December 31st, 2013, were included. Thereafter, a two-year prospective follow-up was performed from January 1st, 2014 to December 31st, 2015.Patients were included if: (a) the symptoms started before age 16 and lasted for at least 6 weeks, (b) fulfilled the ILAR Edmonton 2001 criteria [22], and (c) were receiving synthetic and/or biologic DMARD.

Patients were evaluated every 3 months according to study protocol and local clinical practice. Demographic, clinical, immunologic and treatment data were collected from paper charts and electronic medical records. Uveitis and other non-uveitis comorbidities were considered as separate variables taking into account the clinical relevance of JIA-associated uveitis. Non-uveitis comorbidities were defined as coexisting disorders or diseases, other than uveitis, and not causally related to drug toxicity. DMARDs were initiated in therapeutic doses according to patient's body surface when an optimal control of disease activity could not be attained or when corticosteroids could not be withdrawn along the first 3 months from disease or follow-up onset. Treatment adjustments were performed at scheduled appointments or earlier, if needed, in flare occurrence. DMARD tapering was defined as performing either a dose reduction (below therapeutic dose) or an increase in the interval between doses. When dose tapering was not performed, the DMARD was abruptly withdrawn.

This study was done in accordance with Ethics Research Committees of Vall d'Hebrón University Hospital and Mútua Terrassa University Hospital, in the 
corresponding phases of the study. Written consent was obtained from patients and/or parents.

\section{Clinical remission}

Primary outcome was Clinical Remission (CR) of the disease, defined by Wallace criteria [23, 24] as: (a) no joints with active arthritis, (b) no fever, rash, serositis, splenomegaly or lymphadenopathy attributable to JIA, (c) no active uveitis, (d) Normal erythrocyte sedimentation rate or C-reactive protein level, (e) lowest possible physician's global assessment of disease activity score, and (f) morning stiffness shorter than $15 \mathrm{~min}$. CR on medication was defined as criteria were fulfilled for at least 6 months. $\mathrm{CR}$ off medication was defined as criteria were fulfilled for at least 12 months after all medication was withdrawn [23, 24]. Relapse was defined as no longer fulfilling criteria at one or more visits. To analyse CR according to the therapeutic approach, treatments with DMARD were divided in four groups: 1) synthetic DMARD (sDMARD) alone, 2) sDMARD combined with another sDMARD, 3) sDMARD combined with biologic DMARD (bDMARD), and 4) bDMARD alone. Secondary outcome measures were CR predictive factors, DMARD dose tapering, tapering method and duration, DMARD withdrawal due to $C R$, treatment duration up to withdrawal, relapse after withdrawal, time to relapse and relapse predictive factors. All patients withdrawing any DMARD treatment due to $C R$ fulfilled at least Wallace's criteria of CR on medication.

\section{Statistical analysis}

Qualitative variables were expressed as absolute values and percentages. The normality was explored with the Kolmogorov-Smirnov test. Considering that all study variables presented a non-normal distribution, nonparametric statistics was applied. Quantitative variables were expressed with medians and Interquartile Range (IQR). In bivariate analysis, qualitative variables were compared using the $x^{2}$ test, and the quantitative ones with the Mann-Whitney U test. For significant variables, 95\% CIs were established. For multivariate analysis, logistic and linear regression models were used. Variables finally included in the multivariate model were those showing statistical significance in the bivariate analysis or those with high clinical plausibility. The level of statistical significance was set to 0.05 . Statistical analyses were performed using SPSS 25.0 (SPSS Inc., Armonk, NY, USA).

\section{Results}

A total of 264 patients meeting the ILAR diagnostic criteria for JIA were included, of which 254 had received DMARD (synthetic or biologic). 206 patients were included in the retrospective study, which received 764
DMARD treatments. After 47 subsequent exclusions, 159 patients were included in the prospective study, which received 267 DMARD. At the end of follow-up, 136 patients remained on treatment, with 202 DMARD (Fig. 1).

The cohort was $71 \%$ female and 93\% Caucasian, $52 \%$ had an oligoarticular JIA, $79 \%$ of which were persistent. Patients included had a median age at disease onset of 3 years [Inter quartile range (IQR) 4 years], at diagnosis of 4 years (IQR 5 years) and median disease duration at first DMARD onset of 4 years (IQR 8 years). Antinuclear antibodies (ANA) were detected in $68 \%$ of patients, and HLA B27 in 15\% [67\% of the enthesitis-related arthritis (ERA)]. Uveitis was present in $21 \%$ of patients $(n=43)$. Non-uveitis comorbidities were registered in $20 \%$ of patients $(n=$ $41)$. Of these, $32 \%$ were other autoimmune diseases $(n=13), 32 \%$ genetic mutations or syndromes $(\mathrm{n}=$ 13), $10 \%$ chronic infections $(n=4), 10 \%$ congenital malformations $(\mathrm{n}=4)$, and $16 \%$ miscellanea $(n=7)$. Thirty-two patients associated non-uveitis comorbidities with clinical significance $(78 \%)$, being mild in $38 \%$ of the cases $(n=12)$, moderate in $34 \%(n=11)$ and severe in $28 \%(n=9)$.

Patients who achieved CR at least once throughout study follow-up (Table 1 ) were predominantly Caucasian (94\%), had a persistent oligoarticular JIA (84\%), did not associate non-uveitis comorbidities (87\%), had not presented aprevious DMARD adverse event (75\%), and had not required biologic DMARD $(58 \%)(p<0.05)$. When adjusting the analysis according to the JIA category, these results were confirmed for oligoarticular JIA. ERA patients achieved CR more frequently in the absence of non-uveitis comorbidities $(88 \%, n=15)(p=0.035)$. The significant variables related to ever achieving CR obtained in the multivariate analysis were the absence of both non-uveitis comorbidities $\beta 3.12$ (CI 95\% 1.5-6.51) $(p=0.002)$ and DMARD adverse event $\beta 2.68$ (CI 95\% $1.42-5.07)(p=0.002)$.

\section{Retrospective study}

Throughout the retrospective study, with a median follow-up period of 7 years (IQR 9 years), 764 treatments with DMARD were administered, $75 \%$ with sDMARD $(n=570)$ and $25 \%$ with bDMARD $(n=291)$.

Methotrexate was the sDMARD most frequently dispensed overall $(n=283)$, as the first $(n=169)$ and second $(n=57)$ sDMARD, and alone $(n=157)$. It was more commonly supplied to patients with oligoarticular subtype $(n=157)$, ANA positivity $(n=197)$ and uveitis $(n=$ 63). Moreover, CR was the most frequent reason for its withdrawal $(n=82)$. Other sDMARD administered were Leflunomide (22\%, $n=125)$, Tacrolimus $(7 \%, n=41)$, Cyclosporine A $(7 \%, n=39)$, Sulfasalazine $(5 \%, n=31)$, 


\section{4 eligible JIA patients}

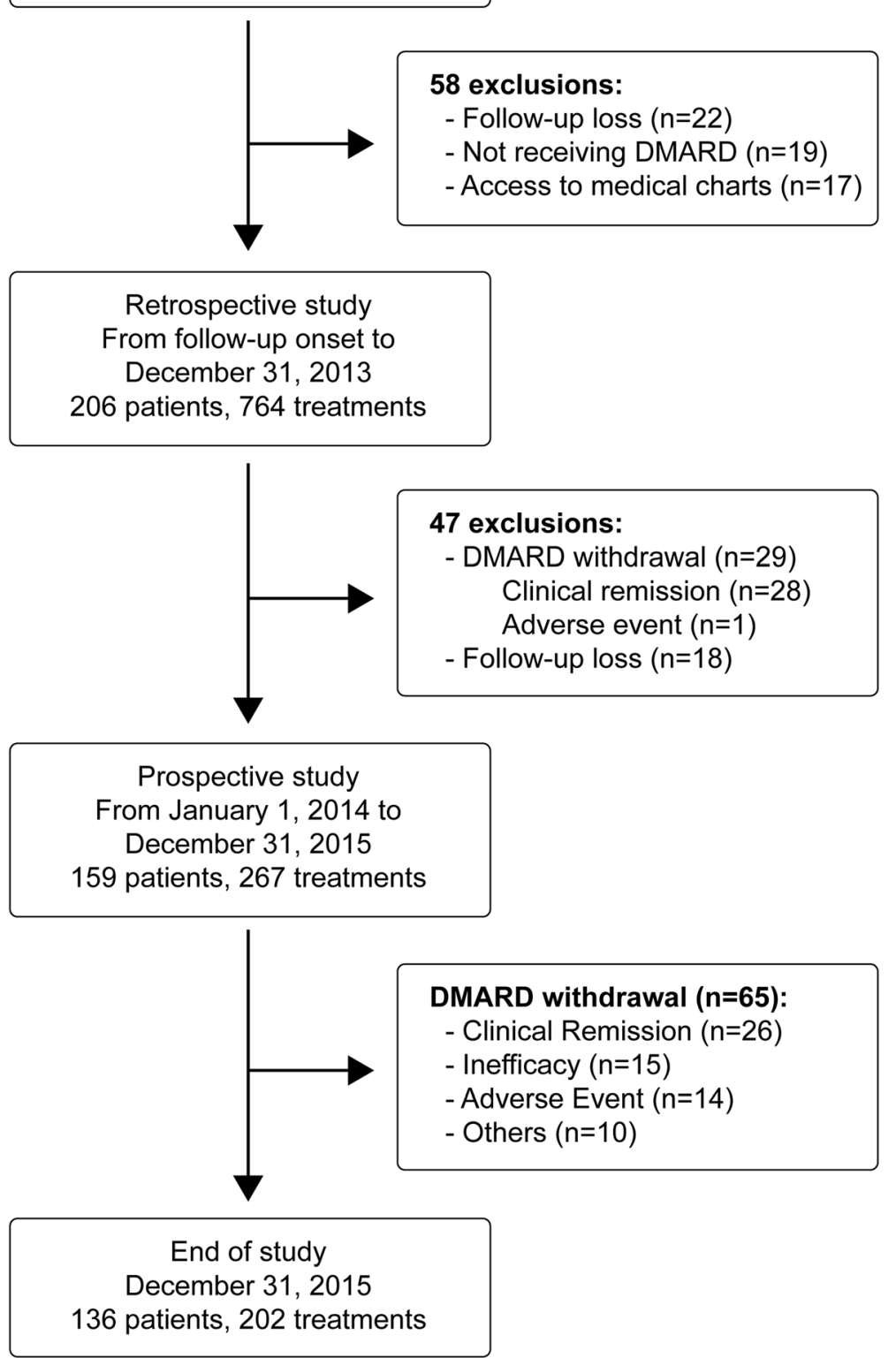

Fig. 1 Cohort of JIA patients: retrospective and prospective studies. From follow-up onset to December 31, 2015

Azathioprine $(4 \%, n=24)$, Mycophenolate mofetil (3\%, $n=15)$ and Hydroxychloroquine $(2 \%, n=12)$.

Etanercept was the most dispensed bDMARD overall (50\%, $n=96)$, as first course $(68 \%, n=65)$, and alone (43\%, $n=42)$. Other dispensed bDMARD were Adalimumab (42\%, $n=55)$ Infliximab (10\%, $n=20)$, Anakinra (5\%, $n=9)$, Tocilizumab $(n=9)$ and others $(n=5)$.

Throughout the retrospective study, $64 \%$ of patients achieved CR at least once (131 of 206). The median number of times that patients achieved CR was 1 (range 1 to 4). A total of 199 treatments were administered amid CR status of the disease (199 of 764). When performing the analysis according to treatment group (Table 2), CR was more frequently observed in patients treated with sDMARD alone (53\%). In this group, CR was associated with oligoarticular persistent subtype and Methotrexate treatment $(p<0.05)$. The absence of HLA B27 and DMARD toxicity were significantly related to higher rates of CR within all treatment groups $(p<0.05)$.

DMARD dose tapering was performed in $66 \%$ of administered treatments. It was more commonly observed in patients treated with sDMARD alone (75\%) and combined with bDMARD $(60 \%)$ groups $(p=0.018)$. No differences were observed regarding tapering method, 
Table 1 Baseline characteristics of JIA patients according to ever achieving clinical remission of the disease

\begin{tabular}{|c|c|c|c|c|}
\hline & $\begin{array}{l}\text { Active Disease } \\
(n=62)\end{array}$ & $\begin{array}{l}\text { Clinical Remission } \\
(n=144)\end{array}$ & $\begin{array}{l}\text { TOTAL } \\
(n=206)\end{array}$ & $p$ \\
\hline Female sex, n (\%) & $44(71)$ & $103(72)$ & $147(71)$ & 0.531 \\
\hline Caucasian ethnicity ${ }^{\mathrm{a}}, \mathrm{n}(\%)$ & $55(89)$ & $136(94)$ & $191(93)$ & 0.016 \\
\hline \multicolumn{5}{|l|}{ JIA subtype $n(\%)$} \\
\hline Oligoarticular & $24(39)$ & $83(58)$ & $107(52)$ & 0.285 \\
\hline Persistent $^{a}$ & $14(58)$ & $70(84)$ & $84(41)$ & 0.016 \\
\hline Extended & $10(42)$ & $13(16)$ & $23(12)$ & \\
\hline Poliarticular RF - & $9(15)$ & $11(8)$ & $20(10)$ & \\
\hline Poliarticular RF + & $2(3)$ & $5(4)$ & $7(3)$ & \\
\hline Psoriatic & $6(10)$ & $11(8)$ & $17(8)$ & \\
\hline Systemic & $4(7)$ & $13(9)$ & $17(8)$ & \\
\hline Enthesitis-related arthritis & $13(21)$ & $17(12)$ & $30(15)$ & \\
\hline Undifferentiated & $3(5)$ & $5(4)$ & $8(4)$ & \\
\hline No uveitis, n (\%) & $47(76)$ & $116(81)$ & $163(79)$ & 0.277 \\
\hline No comorbidities ${ }^{\mathrm{a}}$, n (\%) & $40(65)$ & $125(87)$ & $165(80)$ & 0.001 \\
\hline Positive ANA, n (\%) & $36(58)$ & $103(72)$ & $139(68)$ & 0.067 \\
\hline Positive RF, n (\%) & $3(5)$ & $6(4)$ & $9(4)$ & 0.536 \\
\hline HLA B27 presence, n (\%) & $13(21)$ & $18(13)$ & $31(15)$ & 0.073 \\
\hline No AE with DMARD ${ }^{a}, \mathrm{n}(\%)$ & $30(48)$ & $108(75)$ & $138(67)$ & 0.001 \\
\hline No biologic DMARD ${ }^{a}$, n (\%) & $22(36)$ & $84(58)$ & $106(52)$ & 0.002 \\
\hline
\end{tabular}

$n$ Number, JIA Juvenile idiopathic arthritis, RF- Negative rheumatoid factor, RF+ Positive rheumatoid factor, ANA Antinuclear antibodies, HLA B27 Human leukocyte antigen, $A E$ Adverse event, DMARD Disease modifying antirheumatic drug ${ }^{a} p<0,05$ Statistically significant differences using the $X^{2}$

order (sDMARD or bDMARD first), or duration [median 16 months, (IQR 28)]. Relapse amid dose tapering was scarce in all treatment groups $(14 \%)(p>0.05)$. DMARD withdrawal after dose tapering was significantly higher in patients receiving sDMARD exclusively, alone or combined (86 and $89 \%$, respectively). No significant association was observed between $\mathrm{CR}$ regarding treatment group and disease duration at DMARD onset, the DMAR $\mathrm{D}$ dispensed, or the order in which it was administered.

A total of 124 DMARD treatments were withdrawn due to CR of the disease (62\%). Median treatment duration up to withdrawal was significantly shorter in patients receiving sDMARD alone (31 months, IQR 26 months). Moreover, of these, $64 \%$ relapsed after a median time of 14 months (IQR 32 months). Significantly lower relapse rates were observed in patients with persistent oligoarticular JIA $(93 \%, n=38)(p=0.048)$ and in those in which DMARD dose was tapered before withdrawal $(77 \%, n=50)(p=0.001)$. When performing the analysis according to JIA ILAR category, these results were confirmed for oligoarticular JIA.

Further analysis, adjusting by ILAR category was performed. Significant variables related to clinical remission in patients with oligoarticular forms of JIA are depicted in Table 3. CR predominated in patients receiving sDMARD alone (53\%). Within this group, CR was more commonly observed in patients with persistent forms (92\%), without associated comorbidities (88\%), treated with MTX (80\%) as first DMARD (67\%), and when dose was tapered $(77 \%)(p<0.05)$.

Multivariate analysis demonstrated that variables significantly related to $\mathrm{CR}$ according to treatment group were persistent oligoarticular subtype $(p=0.001)$ and DMARD dose tapering $(p=0.002)$. These results were confirmed in patients with oligoarticular JIA when adjusting by ILAR category $(p<0.001)$.

At the end of the retrospective study, $18 \%$ of patients were in CR off treatment $(n=37)$. Of these, 28 were excluded due to maintaining remission and not requiring DMARD during the prospective study. A total of 236 DMARD were yet being administered, 60 of which were dispensed to patients in CR status of the disease. DMAR $\mathrm{D}$ treatment continuation predominated in patients in CR receiving bDMARD, alone (63\%) and combined with $\operatorname{sDMARD}(48 \%)(p=0.001)$.

\section{Prospective study}

Clinical remission was achieved by $17 \%$ of patients throughout the two-year follow-up prospective study (27 out of 159 patients). A total of 57 DMARD treatments were administered to patients in CR status of the disease (57 out of 267). 
Table 2 Clinical remission in JIA patients treated with DMARD according to treatment group. Retrospective study results

\begin{tabular}{|c|c|c|c|c|c|c|}
\hline & $\begin{array}{l}\text { SDMARD } \\
\text { alone } \\
n=106(53 \%)\end{array}$ & $\begin{array}{l}\text { SDMARD } \\
\text { combined } \\
n=37(19 \%)\end{array}$ & $\begin{array}{l}\text { SDMARD BDMARD } \\
\text { combined } \\
n=48(24 \%)\end{array}$ & $\begin{array}{l}\text { BDMARD } \\
\text { alone } \\
n=8(4 \%)\end{array}$ & $\begin{array}{l}\text { Clinical } \\
\text { remission } \\
n=199\end{array}$ & $p$ \\
\hline \multicolumn{7}{|l|}{ JIA ILAR category ${ }^{a} \mathrm{n}(\%)$} \\
\hline Oligoarticular & $66(62)$ & $18(49)$ & $25(52)$ & $3(1)$ & $112(56)$ & 0.003 \\
\hline Persistent & $61(92)$ & $13(72)$ & $17(68)$ & $1(33)$ & $92(82)$ & \\
\hline HLA B27 absence ${ }^{a} \mathrm{n}(\%)$ & $89(84)$ & $33(89)$ & $25(52)$ & $6(75)$ & $153(85)$ & 0,023 \\
\hline \multicolumn{7}{|l|}{ Synthetic DMARD a $\mathrm{n}(\%)$} \\
\hline Metotrexate & $78(74)$ & $18(49)$ & $15(31)$ & 0 & $108(54)$ & $<0.001$ \\
\hline No AE with DMARD ${ }^{a} \mathrm{n}(\%)$ & $81(76)$ & $24(65)$ & $33(69)$ & $1(13)$ & $139(70)$ & 0.005 \\
\hline \multicolumn{7}{|l|}{ Dose tapering $n=132$} \\
\hline Dose tapering ${ }^{a} \mathrm{n}(\%)$ & $80(75)$ & $18(49)$ & $29(60)$ & $5(62)$ & $132(66)$ & 0,018 \\
\hline Tapering method n (\%) & & & & & & 0,071 \\
\hline Interval increase & $35(44)$ & $8(44)$ & $12(41)$ & $5(100)$ & $60(45)$ & \\
\hline Dose decrease & $30(37)$ & $7(39)$ & $15(31)$ & 0 & $46(35)$ & \\
\hline Both & $15(19)$ & $3(17)$ & $1(3)$ & 0 & $19(14)$ & \\
\hline Tapering duration, months, median (IQR) & $15(20)$ & $14(27)$ & $21(25)$ & $40(30)$ & $16(28)$ & 0,190 \\
\hline Relapse amid tapering, n (\%) & $10(13)$ & $5(28)$ & $4(14)$ & 0 & $19(14)$ & 0,330 \\
\hline Withdrawal after tapering ${ }^{\mathrm{a}}, \mathrm{n}(\%)$ & $69(86)$ & $16(89)$ & $10(34)$ & $1(13)$ & $95(72)$ & $<0,001$ \\
\hline \multicolumn{7}{|l|}{ Withdrawal due to $C R n=124$} \\
\hline Withdrawal due to CR & $71(67)$ & $29(78)$ & $21(44)$ & $3(38)$ & $124(62)$ & 0,728 \\
\hline $\begin{array}{l}\text { Treatment duration to withdrawal due to } \\
\mathrm{RC}^{\mathrm{a}} \text {, months, median (IQR) }\end{array}$ & $31(26)$ & $42(43)$ & $34(54)$ & $68(71)$ & $31(30)$ & 0,037 \\
\hline Relapse after withdrawal n (\%) & $50(70)$ & $16(55)$ & $11(52)$ & $2(67)$ & $79(64)$ & 0,783 \\
\hline Time to relapse, months, median (IQR) & $13(25)$ & $42(41)$ & $10(18)$ & 14 & $14(32)$ & 0,122 \\
\hline
\end{tabular}

SDMARD Synthetic disease modifying drug, BDMARD Biologic disease modifying drug, JIA Juvenile idiopathic arthritis, $n$ Number, HLA B27 Human leukocyte antigen, $A E$ Adverse event, IQR Interquartile range, $C R$ Clinical remission

${ }^{a} p<0,05$ Statistically significant differences using the $X^{2}$ or Mann Whitney $U$ tests

Patients demographic, clinical and treatment variables significantly related to $\mathrm{CR}$, according to treatment group, are summarized in Table 4. Clinical Remission predominated in female patients in all treatment groups, except in the sDMARD and bDMARD combined group $(p=0.037)$. Persistent oligoarticular forms, ANA positivity, HLA B27 and uveitis absence were related to CR, particularly in patients treated with sDMARD alone $(p<$ 0.05 ). When adjusting by JIA category, ANA association with $\mathrm{CR}$ was confirmed for oligoarticular and psoriatic subtypes and HLA B27 for oligoarticular and ERA subtypes in those patients treated with SDMARD alone $(p<$ 0.05). Two variables were significantly related to CR according to treatment group in multivariable model:

Table 3 Clinical remission according to treatment group in patients with oligoarticular JIA

\begin{tabular}{|c|c|c|c|c|c|c|}
\hline & $\begin{array}{l}\text { SDMARD } \\
\text { alone } \\
n=66\end{array}$ & $\begin{array}{l}\text { SDMARD } \\
\text { combined } \\
n=18\end{array}$ & $\begin{array}{l}\text { SDMARD BDMARD } \\
\text { combined } \\
n=25\end{array}$ & $\begin{array}{l}\text { BDMARD } \\
\text { alone } \\
n=3\end{array}$ & $\begin{array}{l}\text { Clinical } \\
\text { remission } \\
n=112\end{array}$ & $p$ \\
\hline Persistent & $61(92)$ & $13(72)$ & $17(68)$ & $1(33)$ & $92(46)$ & 0.003 \\
\hline Comorbidities ${ }^{b}$ absence, $\mathrm{n}(\%)$ & $58(88)$ & $15(83)$ & $23(92)$ & $1(33)$ & $97(87)$ & 0.042 \\
\hline \multicolumn{7}{|l|}{ Synthetic DMARD ${ }^{a}, \mathrm{n}(\%)$} \\
\hline Metotrexate & $53(80)$ & $9(50)$ & $8(50)$ & 0 & $70(35)$ & 0.025 \\
\hline First DMARD course ${ }^{c}, \mathrm{n}(\%)$ & $44(67)$ & $6(28)$ & $11(44)$ & 0 & $60(54)$ & 0.014 \\
\hline DMARD dose tapering ${ }^{a}, \mathrm{n}(\%)$ & $51(77)$ & $8(44)$ & $15(60)$ & $3(100)$ & $77(69)$ & 0.024 \\
\hline
\end{tabular}

SDMARD Synthetic disease modifying drug, BDMARD Biologic disease modifying drug, JIA Juvenile idiopathic arthritis, $n$ Number;

${ }^{a} p<0,05$ Statistically significant differences using the $x^{2}$ test

${ }^{b}$ Comorbidities other than uveitis and not related to drug toxicity

${ }^{c}$ First DMARD course $=$ DMARD dispensed in the first place, chronologically 
Table 4 Clinical remission in JIA patients treated with DMARD according to treatment group. Prospective study results

\begin{tabular}{|c|c|c|c|c|c|c|}
\hline & $\begin{array}{l}\text { SDMARD } \\
\text { alone } \\
n=33(43 \%)\end{array}$ & $\begin{array}{l}\text { SDMARD } \\
\text { combined } \\
n=6(8 \%)\end{array}$ & $\begin{array}{l}\text { SDMARD BDMARD } \\
\text { combined } \\
n=23(30 \%)\end{array}$ & $\begin{array}{l}\text { BDMARD } \\
\text { alone } \\
n=14(18 \%)\end{array}$ & $\begin{array}{l}\text { Clinical } \\
\text { remission } \\
n=76\end{array}$ & $p$ \\
\hline Female sex ${ }^{a}, \mathrm{n}(\%)$ & $24(73)$ & $4(67)$ & $8(35)$ & $9(64)$ & $45(59)$ & 0.037 \\
\hline Persistent oligoarticular ${ }^{\mathrm{a}}$, n (\%) & $19(91)$ & $6(100)$ & $4(57)$ & $2(50)$ & $31(82)$ & 0.048 \\
\hline ANA positivity ${ }^{a}, \mathrm{n}(\%)$ & $26(79)$ & $6(100)$ & $12(52)$ & $6(43)$ & $50(66)$ & 0.013 \\
\hline HLA B27 absence ${ }^{a}$, n (\%) & $31(94)$ & 0 & $12(52)$ & $8(57)$ & $57(75)$ & 0.005 \\
\hline Uveitis absence ${ }^{\mathrm{a}}$, n (\%) & $27(82)$ & $2(33)$ & $21(91)$ & $13(93)$ & $63(83)$ & 0.006 \\
\hline \multicolumn{7}{|l|}{ Biologic DMARD ${ }^{a}$, n (\%) } \\
\hline Etanercept & 0 & 0 & $5(36)$ & $10(71)$ & $15(54)$ & 0.040 \\
\hline DMARD dose tapering ${ }^{a}, \mathrm{n}(\%)$ & $29(88)$ & $3(50)$ & $14(61)$ & $11(79)$ & $57(75)$ & 0.050 \\
\hline
\end{tabular}

SDMARD Synthetic disease modifying drug, BDMARD Biologic disease modifying drug, JIA Juvenile idiopathic arthritis, $n$ Number; $A N A$ Antinuclear antibodies, HLA $B 27$ Human leukocyte antigen, $A E$ Adverse event; IQR Interquartile range, $C R$ Clinical remission

${ }^{a} p<0,05$ Statistically significant differences using the $X^{2}$ or Mann Whitney $U$ tests

ANA $(p=0.034)$ and HLA B27 $(p=0.033)$. ANA negativity demonstrated a negative association with $\mathrm{CR}$ in patients treated with sDMARD alone $\beta-1.59$ (CI 95\% $0.43-0.955)(p=0.044)$.

DMARD dose was tapered in $74 \%$ of treatments, with median of two reductions per treatment (range 1 to 5). Dose tapering predominated in patients treated with synthetic or biologic DMARD administered alone (88 and $79 \%$, respectively) $(p=0.050)$. No differences in method, order, or duration (median 24 months, IQR 29) were observed among treatment groups. Relapse throughout dose tapering was scarce (11\%) and 39\% of DMARD treatments were subsequently withdrawn, showing no significant differences regarding treatment $(p>0.05)$. Out of 267 treatments administered, 34\% were withdrawn due to CR of the disease $(n=26)$ with median treatment duration to withdrawal of 12 months (IQR 11$)$ and $12 \%$ of relapse $(n=3)$. Median time to relapse was 10 months, comparable in all treatment groups $(p>0.05)$.

To conclude, when the follow-up was completed, 70\% of the patients in the cohort had attained CR at least once (144 out of 206), and 29\% were in CR off all medication (59 out of 206). Of these, 69\% achieved CR off medication throughout the retrospective study and maintained it along the 24-month prospective study $(n=41)$. Clinical remission off medication $(n=59)$, regarding JIA subtype, was attained by 30 oligoarticular, 11 ERA, 10 systemic, 4 poliarticular RF negative, 3 undifferentiated and 1 poliarticular RF positive patients.

\section{Discussion}

Clinical remission of the disease, based on Wallace criteria, was achieved at least once by $70 \%$ of the JIA patients included in the cohort along a median of 9-year follow-up, and was the main reason of DMARD withdrawal in both studies.
Greater $\mathrm{CR}$ rates were observed along retrospective study, which might be explained by the longer follow-up duration. In accordance with this observation, two studies have hypothesized, based on study results observed throughout last decade, that CR on medication increases with longer disease duration $[9,17]$.

In our study, patients were predominantly Caucasian females, with early JIA onset ( $<5$ years), oligoarticular persistent JIA, ANA positivity and early age at DMARD onset ( $<6$ years). MTX was the most frequently administered SDMARD and the most commonly administered alone.

Ever attaining CR was related to persistent oligoarticular subtype, absence of coexisting comorbidities (other than uveitis) and not having undergone an adverse event with DMARD therapy. These results were confirmed for oligoarticular JIA patients, among which CR predominated in those treated with Methotrexate alone and as first DMARD. Patients with oligoarticular JIA, particularly those with persistent subtype, have achieved the highest CR rates on and off medication in various studies, being treated in most cases with MTX as DMARD of choice [17, 25-27].

On the other hand, coexisting comorbidities in JIA patients, including other autoimmune diseases, genetic syndromes, or chronic infections, among others, could lead to both: a higher occurrence of DMARD toxicity and inefficacy. Raab et al. studied associated comorbidities in young adult JIA patients of the JuMBO register and concluded that comorbidities have a significant impact on disease activity and global health status [28]. Furthermore, Simon et al. have recently put in evidence that patients with JIA are more likely to have concurrent autoimmune diseases, and this association might have an important role in JIA treatment decisions and outcomes [29].

Lastly, the negative influence of DMARD toxicity in ever achieving CR in JIA patients could be explained in 
those having a more aggressive course of the disease. In these, higher DMARD doses and therapeutic targets are combined, leading to a greater likelihood of DMARD withdrawal due to drug toxicity and subsequent poorer control of disease activity.

According to therapeutic approach, CR was observed in patients treated with synthetic DMARD alone more than half of the times, being Methotrexate the most administered sDMARD and being CR the predominant reason of its withdrawal. These findings support that Methotrexate is still the DMARD of choice in most JIA categories, even in the biologic era $[10,30,31]$. Within this group CR was associated with female sex, persistent oligoarticular subtype, absence of comorbidities (other than uveitis) and Methotrexate treatment as first DMARD course. ANA positivity, the absence of HLA B27, uveitis and DMARD toxicity, and having performed DMARD dose tapering were related to higher $C R$ rates within all treatment groups, but more significantly to patients treated with sDMARD alone. Furthermore, ANA association with CR was confirmed for oligoarticular and psoriatic subtypes and HLA B27 for oligoarticular and ERA subtypes in those patients treated with sDMARD alone. However, the results must be considered cautiously, since the number of patients in some categories was scarce.

The role of ANA positivity in the likelihood of achieving and sustaining CR, and therefore, in short and longterm outcomes, has not yet been clarified. Some studies suggest that ANA negativity would lead to a poorer response to MTX throughout the first 6 months of the disease, a higher active joint count along the first 6 to 24 months, regardless on active joint count, and to a persistent active disease through the first 3 years from JIA onset [25, 32-34]. The possible association between ANA positivity and a better MTX response would explain that oligoarticular patients included in the study, and not having coexistent comorbidities (uveitis or others), would have solely required treatment with Methotrexate alone to attain CR. These results would support what has been recently suggested in two studies which showed that JIA patients with early onset, ANA positivity and lower active joint count, constitute a homogeneous JIA subtype with less aggressive course of the disease, higher likelihood of achieving CR and subsequently better outcome [35, 36]. Nevertheless, our results contravene the results obtained in two other studies which suggest that ANA status does not alter remission rates nor JIA outcome [37, 38].

Regarding HLA B27, several studies have put in evidence that HLA B27 presence in JIA patients leads to a higher risk of bone erosions and radiologic structural damage appearance $[39,40]$, a more persistent and extended course of the disease [41, 42], and a lower likelihood of achieving clinical remission [12, 25].
Dose tapering was performed in two thirds of patients in CR on medication. Relapse throughout dose tapering was scarce in both studies. Two thirds of DMARD treatments administered along CR of the disease were withdrawn throughout our retrospective study, with a subsequent relapse observed in two thirds of the cases, after a median time to relapse of about 12 months with comparable results in all treatment groups. Significant lower rates of relapse after withdrawal were observed in patients with persistent oligoarticular JIA, treated with sDMARD alone (mostly Methotrexate) in which the drug dose was previously tapered. Nonetheless, no differences in method, order (sDMARD or bDMARD first) or duration (median longer than 12 months in both studies) of dose tapering were observed within treatment groups in both studies, and neither was associated with $\mathrm{CR}$ of the disease nor relapse after withdrawal. Regarding patients in $\mathrm{CR}$ on medication, our therapeutic strategy is comparable to the one performed by most rheumatologists participating in two survey studies, who would wait at least 12 months while in CR on medication to start considering DMARD tapering or withdrawal $[14,15]$. Furthermore, given that $C R$ was more frequently achieved in patients treated with MTX alone in our study, these results would support that maintaining MTX at least for 12 months after achieving CR before withdrawal is associated with a higher likelihood of maintaining remission off treatment, as suggested by Klotscheet al [43]. One of the limitations of our study is that the exact date of clinical remission start was unavailable in most patients, and therefore, total duration of CR on treatment could not be measured. Duration of $\mathrm{CR}$ on medication remains currently of significant interest given that its association with relapse after treatment discontinuation has shown conflicting results [13].

When the study finalised after a median follow-up time of 9 years, more than two thirds had attained CR at least once, and nearly one third of patients were in clinical remission off all medication, which is slightly lower than the $42 \%$ observed in Nordalet al. study [44]. Considering that in our study persistent oligoarticular JIA is the most prevalent JIA subtype, we might have underestimated CR rates through follow-up losses, given that patients lost to follow up would more likely be in remission than those who maintain it.

On the other hand, two thirds were still on DMARD therapy. It should be noted that in those patients treated with SDMARD and bDMARD combined, tapering duration and number of times the dose was tapered were greater, whereas subsequent withdrawal and following flares were less frequently observed in the prospective study. This fact would support the recently growing belief that in some patients, especially those with persistent and extended poliarticular RF positive, systemic or ERA 
JIA, the disease behaves more aggressively, needing more specific therapeutic targets and a sustained treatment over time, even when CR is achieved. In those scenarios, maintaining a minimum and progressively tapered dose for at least 12 months (before even considering withdrawal) would appear to be a good therapeutic approach to minimize subsequent relapses.

The main limitation of our study is its observational mono-centric and non-controlled design. This fact might have led to selection bias, having a lower number of patients included in a predominantly oligoarticular JIA cohort. Consequently, the depicted results should be applied cautiously to other JIA categories. That being said, the coincidence of the results obtained in both retrospective and prospective studies grants coherence to the conclusions provided. Lastly, this study fails to describe total duration of $\mathrm{CR}$ both on and off medication as the exact date of $\mathrm{CR}$ onset was unavailable in most patients. Clinical remission's survival in JIA patients remains an issue of great concern given the complexity of establishing and defining when $C R$ itself begins.

\section{Conclusions}

More than two thirds of JIA patients attained CR along the 9 years of follow-up, and nearly one third achieved CR off medication. Females with early JIA onset, lower active joint count and ANA positivity were the ones achieving and sustaining remission more frequently, especially when receiving synthetic DMARD alone and in the absence of HLA B27, comorbidities or previous DMARD toxicity. In patients who already have attained remission, a progressive DMARD dose tapering for at least 1 year before considering withdrawal would minimize the probability of subsequent relapse, particularly in those who required a biologic DMARD to achieve a quiescent state of the disease.

\section{Abbreviations}

JIA: Juvenile Idiopathic Arthritis; CR: Clinical Remission; DMARD: Disease Modifying Antirheumatic Drugs; ANA: Antinuclear Antibodies; RF: Rheumatoid Factor; HLA: Human Leukocyte Antigen; ERA: Enthesitis Related Arthritis; IQR: Interquartile Range; MTX: Methotrexate

\section{Acknowledgements}

The authors wish to express their gratitude to Ms. Patricia Vigués for revising the language and Mr. Manel Martori for helping in graphics layout.

\section{Authors' contributions}

MCV and CM conceived the original research idea. MCV, NG and CM designed the study. MCV and JLT carried out the data collection. MCV, SQ and NG performed the statistical analysis. MCV, NG, SQ and CM interpreted the results. MCV wrote the manuscript. All authors reviewed and approved the final version of the manuscript. MVC is guarantor of the paper. All authors read and approved the final version of the manuscript.

\section{Availability of data and materials}

The datasets used and/or analysed during the current study are available from the corresponding author on reasonable request.

\section{Declarations}

Ethics approval and consent to participate

this study was done in accordance with Ethics Research Committees of Val d'Hebron University Hospital and Mútua Terrassa University Hospital, in the corresponding phases of the study.

\section{Consent for publication}

Written consent was obtained from all patients and/or parents.

\section{Competing interests}

None declared.

\section{Author details}

${ }^{1}$ Department of Rheumatology, Hospital UniversitariSagrat Cor, C/ Londres, 28-38 3rd floor, 08029 Barcelona, Spain. ${ }^{2}$ Department of Rheumatology, Hospital UniversitariMútua Terrassa, Terrassa, Spain. ${ }^{3}$ Department of Rheumatology, Pediatric Rheumatology Unit, Hospital

UniversitariValld'Hebrón, Barcelona, Spain. ${ }^{4}$ Departament de Farmacologia, Terapèutica i Toxicologia, UniversitatAutònoma de Barcelona, Barcelona, Spain. ${ }^{5}$ Research Unit, University Hospital of Mútua Terrassa, Research Foundation Mútua Terrassa, Universitat de Barcelona, Barcelona, Spain. ${ }^{6}$ Hospital Sant Jaume de Calella, Laboratori de Referència de Catalunya i Corporació de Salut del Maresme i la Selva, Barcelona, Spain. ${ }^{7}$ Departament of Rheumatology and Systemic Autoimmune Diseases, Hospital de la Santa Creu i Sant Pau, Universitat Autònoma de Barcelona, Barcelona, Spain.

${ }^{8}$ Departament de Medicina, Universitat Autònoma de Barcelona, Barcelona, Spain. ${ }^{9}$ Retired, Barcelona, Spain. ${ }^{10}$ Department of Rheumatology, Hospital Universitario de Cruces, Barakaldo, Spain.

Received: 28 January 2021 Accepted: 31 May 2021

Published online: 21 August 2021

\section{References}

1. Ravelli A, Martini A. Juvenile idiopathic arthritis. Lancet. 2007;369(9563):76778. https://doi.org/10.1016/S0140-6736(07)60363-8.

2. Martini A, Ravelli A, Avcin T, Beresford MW, Burgos-Vargas R, Cuttica R, et al. Toward new classification criteria for juvenile idiopathic arthritis: first steps. Pediatric rheumatology international trials organization international consensus. J Rheumatol. 2019;46(2):190-7. https://doi.org/1 0.3899/jrheum.180168.

3. Dave M, Rankin J, Pearce M, Foster HE. Global prevalence estimates of three chronic musculoskeletal conditions: Club foot, juvenile idiopathic arthritis and juvenile systemic lupus erythematosus. Pediatr Rheumatol Online J. 2020:18:1-7.

4. Shoop-Worrall SJ, Oude Voshaar MA, McDonagh JE, van de Laar MA, Wulffraat N, Thomson W, et al. A common functional ability score for young people with juvenile idiopathic arthritis. Arthritis Care Res (Hoboken). 2020; 73(7):947-54. https://doi.org/10.1002/acr.24204.

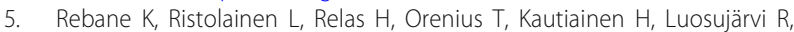
et al. Disability and health-related quality of life are associated with restricted social participation in young adults with juvenile idiopathic arthritis. Scand J Rheumatol. 2019;48(2):105-13. https://doi.org/10.1080/ 03009742.2018.1493140

6. Tynjälä P, Vähäsalo P, Tarkiainen $M$, Kröger L, Aalto K, Malin M, et al. Aggressive combination drug therapy in very early polyarticular juvenile idiopathic arthritis (ACUTE-JIA): a multicentre randomised open-label clinical trial. Ann Rheum Dis. 2011;70(9):1605-12. https://doi.org/10.1136/ard.201 0.143347 .

7. Wallace CA, Giannini EH, Spalding SJ, Hashkes PJ, O'Neil KM, Zeft AS, et al. Trial of early aggressive therapy in polyarticular juvenile idiopathic arthritis. Arthritis Rheum. 2012;64(6):2012-21. https://doi.org/10.1002/art.34343.

8. Minden $K$, Horneff $G$, Niewerth M, Seipelt E, Aringer M, Aries P, et al. Time of disease-modifying antirheumatic drug start in juvenile idiopathic arthritis and the likelihood of a drug-free remission in young adulthood. Arthritis Care Res. 2019;71(4):471-81. https://doi.org/10.1002/acr.23709.
Funding

None declared. 
9. Klein-wieringa IR, Brinkman DMC, Hissink PCE. Update on the treatment of nonsystemic juvenile idiopathic arthritis including treatment-to-target: is (drug-free) inactive disease already possible? Curr Opin Rheumatol. 2020; 32(5):403-13. https://doi.org/10.1097/BOR.0000000000000727.

10. Giancane $G$, Ruperto N. Treatment of juvenile idiopathic arthritis: what's new? Curr Opin Rheumatol. 2019;31(5):428-35. https://doi.org/10.1097/BOR. 0000000000000632.

11. Consolaro A, Giancane G, Schiappapietra B, Davì S, Calandra S, Lanni S, et al. Clinical outcome measures in juvenile idiopathic arthritis. Pediatr Rheumatol Online J. 2016;14:1-8.

12. Minden K, Kiessling U, Listing J, Niewerth M, Döring E, Meincke J, et al. Prognosis of patients with juvenile chronic arthritis and juvenile spondyloarthropathy. J Rheumatol. 2000;27(9):2256-63.

13. Halyabar O, Mehta J, Ringold S, Rumsey DG, Horton DB. Treatment withdrawal following remission in juvenile idiopathic arthritis: a systematic review of the literature. Paediatr Drugs. 2019;21(6):469-92. https://doi.org/1 0.1007/s40272-019-00362-6

14. Azevedo SA, Ramos Rodrigues J, Guimarães F, Almeida D, Pinto AS, Parente $\mathrm{H}$, et al. Strategies for the withdrawal of classic and biological DMARD in clinically inactive patients with juvenile idiopathic arthritis. Acta Reumatol Port. 2020;45(3):229-32.

15. Horton DB, Onel KB, Beukelman T, Ringold S. Attitudes and approaches for withdrawing drugs for children with clinically inactive nonsystemic JIA: a survey of the childhood arthritis and rheumatology research alliance. J Rheumatol. 2017:44(3):352-60. https://doi.org/10.3899/jrheum.161078.

16. Prince FH, Twilt M, Simon SC, van Rossum MA, Armbrust W, Hoppenreijs EP, et al. When and how to stop etanercept after successful treatment of patients with juvenile idiopathic arthritis. Ann Rheum Dis. 2009;68(7):1228-9. https://doi.org/10.1136/ard.2008.101030.

17. Shoop-Worrall SJW, Kearsley-Fleet L, Thomson W, Verstappen SMM, Hyrich $\mathrm{KL}$. How common is remission in juvenile idiopathic arthritis: a systematic review. Semin Arthritis Rheum. 2017;47(3):331-7. https://doi.org/10.1016/j. semarthrit.2017.05.007.

18. Shoop-Worrall SJW, Verstappen SMM, McDonagh JE, Baildam E, Chieng A, Davidson J, et al. Long-term outcomes following achievement of clinically inactive disease in juvenile idiopathic arthritis: the importance of definition. Arthritis Rheumatol. 2018;70(9):1519-29. https://doi.org/10.1002/art.40519.

19. Cai $Y$, Liu $X$, Zhang $W, X u$ J, Cao L. Clinical trial of etanercept tapering in juvenile idiopathic arthritis during remission. Rheumatol Int. 2013;33(9): 2277-82. https://doi.org/10.1007/s00296-012-2642-7.

20. Chang CY, Meyer RML, Reiff AO. Impact of medication withdrawal method on flare-free survival in patients with juvenile idiopathic arthritis on combination therapy. Arthritis Care Res (Hoboken). 2015;67(5):658-66. https://doi.org/10.1002/acr.22477.

21. Modesto C, Antón J, Rodriguez B, Bou R, Arnal C, Ros J, et al. Incidence and prevalence of juvenile idiopathic arthritis in Catalonia (Spain). Scand J Rheumatol. 2010;39(6):472-9. https://doi.org/10.3109/03009741003742722.

22. Petty RE, Southwood TR, Manners P, Baum J, Glass DN, Goldenberg J, et al. International league of associations for rheumatology classification of juvenile idiopathic arthritis: second revision, Edmonton, 2001. J Rheumatol. 2004;31:390-2

23. Wallace CA, Ruperto N, Giannini E. Preliminary criteria for clinical remission for select categories of juvenile idiopathic arthritis. J Rheumatol. 2004;31(11): 2290-4.

24. Wallace CA, Giannini EH, Huang BIN, Itert L. American College of Rheumatology Provisional Criteria for defining clinical inactive disease in select categories of juvenile idiopathic arthritis. Arthritis Care Res. 2011;63(7): 929-36. https://doi.org/10.1002/acr.20497.

25. Glerup M, Herlin T, Twilt M. Clinical outcome and long-term remission in JIA. Curr Rheumatol Rep. 2017;19(12):75. https://doi.org/10.1007/s11926-0170702-4.

26. Shenoi $S$, Wallace CA. Remission in juvenile idiopathic arthritis: current facts. Curr Rheumatol Rep. 2010;12(2):80-6. https://doi.org/10.1007/s11926-0100085-2.

27. Guzman J, Oen K, Tucker LB, Huber AM, Shiff N, Boire G, et al. The outcomes of juvenile idiopathic arthritis in children managed with contemporary treatments: results from the reacch-out cohort. Ann Rheum Dis. 2015;74(10):1854-60. https://doi.org/10.1136/annrheumdis-2014-205372.

28. Raab A, Sengler C, Niewerth M, Klotsche J, Horneff G, Zink A, et al. Comorbidity profiles among adult patients with juvenile idiopathic arthritis: results of a biologic register. Clin Exp Rheumatol. 2013;31(5):796-802.
29. Simon TA, Harikrishnan GP, Kawabata H, Singhal S, Brunner HI, Lovell DJ. Prevalence of co-existing autoimmune disease in juvenile idiopathic arthritis: a cross-sectional study. Pediatr Rheumatol Online J. 2020;18(1):43. https://doi.org/10.1186/s12969-020-00426-9.

30. Hügle $B$, Horneff $G$. The role of synthetic drugs in the biologic era: therapeutic strategies for treating juvenile idiopathic arthritis. Expert Opin Pharmacother. 2016;17(5):703-14. https://doi.org/10.1517/14656566.201 6.1133592 .

31. Barut K, Adrovic A, Şahin S, Kasapçopur Ö. Juvenile idiopathic arthritis. Balkan Med J. 2017;34(2):90-101. https://doi.org/10.4274/balkanmedj.2017.0111.

32. Selvaag AM, Flatø B, Dale K, Lien G, Vinje O, Smerdel-Ramoya A, et al. Radiographic and clinical outcome in early juvenile rheumatoid arthritis and juvenile spondyloarthropathy: a 3-year prospective study. J Rheumatol. 2006;33(7):1382-91.

33. Vilca I, Munitis PG, Pistorio A, Ravelli A, Buoncompagni A, Bica B, et al. Predictors of poor response to methotrexate in polyarticular-course juvenile idiopathic arthritis: analysis of the PRINTO methotrexate trial. Ann Rheum Dis. 2010;69(8):1479-83. https://doi.org/10.1136/ard.2009.120840.

34. van Dijkhuizen EH, Wulffraat NM. Prediction of methotrexate efficacy and adverse events in patients with juvenile idiopathic arthritis: a systematic literature review. Pediatr Rheumatol Online J. 2014;12(1):51. https://doi.org/1 0.1186/1546-0096-12-51.

35. Ravelli A, Felici E, Magni-Manzoni S, Pistorio A, Novarini C, Bozzola E, et al. Patients with antinuclear antibody-positive juvenile idiopathic arthritis constitute a homogeneous subgroup irrespective of the course of joint disease. Arthritis Rheum. 2005;52(3):826-32. https://doi.org/10.1002/art.20945.

36. Ma X, Xin L, Sun J, Liu Z. Antinuclear antibody-positive cohort constitutes homogeneous entity in juvenile idiopathic arthritis. Mod Rheumatol. 2016: 26(1):75-9. https://doi.org/10.3109/14397595.2015.1056993.

37. Glerup M, Herlin T, Twilt M. Remission rate is not dependent on the presence of antinuclear antibodies in juvenile idiopathic arthritis. Clin Rheumatol. 2017;36(3):671-6. https://doi.org/10.1007/s10067-017-3540-x.

38. Albers HM, Brinkman DM, Kamphuis SS, van Suijlekom-Smit LW, van Rossum $M A$, Hoppenreijs EP, et al. Clinical course and prognostic value of disease activity in the first two years in different subtypes of juvenile idiopathic arthritis. Arthritis Care Res (Hoboken). 2010;62(2):204-12. https://doi.org/10.1 002/acr.20069

39. Flatø B, Lien G, Smerdel A, Vinje O, Dale K, Johnston V, et al. Prognostic factors in juvenile rheumatoid arthritis: a case-control study revealing early predictors and outcome after 14.9 years. J Rheumatol. 2003;30(2):386-93.

40. van Rossum MA, Zwinderman AH, Boers M, Dijkmans BA, van Soesbergen RM, Fiselier TJW, et al. Radiologic features in juvenile idiopathic arthritis: a first step in the development of a standardized assessment method. Arthritis Rheum. 2003;48(2):507-15. https://doi.org/10.1002/art.10783.

41. Berntson L, Damgård M, Andersson-Gäre B, Herlin T, Nielsen S, Nordal E, et al. HLA-B27 predicts a more extended disease with increasing age at onset in boys with juvenile idiopathic arthritis. J Rheumatol. 2008;35(10): 2055-61.

42. Berntson L, Nordal E, Aalto K, Peltoniemi S, Herlin T, Zak M, et al. HLA-B27 predicts a more chronic disease course in an 8-year follow-up cohort of patients with juvenile idiopathic arthritis. J Rheumatol. 2013;40(5):725-31. https://doi.org/10.3899/jrheum.121257.

43. Klotsche J, Minden K, Niewerth M, Horneff G. Time spent in inactive disease before MTX withdrawal is relevant with regard to the flare risk in patients with JIA. Ann Rheum Dis. 2018;77(7):996-1002. https://doi.org/10.1136/a nnrheumdis-2017-211968.

44. Nordal E, Zak M, Aalto K, Berntson L, Fasth A, Herlin T, et al. Ongoing disease activity and changing categories in a long-term nordic cohort study of juvenile idiopathic arthritis. Arthritis Rheum. 2011;63(9):2809-18. https:// doi.org/10.1002/art.30426.

\section{Publisher's Note}

Springer Nature remains neutral with regard to jurisdictional claims in published maps and institutional affiliations. 